\title{
Failure After Multiple Treatments
}

National Cancer Institute

\section{Source}

National Cancer Institute. Failure After Multiple Treatments. NCI Thesaurus. Code C102636.

A lack of response to more than one cycle of therapy. 